\title{
A Systematic Review of Abdominal Imaging Findings in COVID-19 Patients
}

\author{
Priya Singh $^{\mathrm{a}}$ Surya Pratap Singh ${ }^{\mathrm{b}} \quad$ Amit Kumar Verma $^{\mathrm{a}}$ \\ Sreenivasa Narayana Raju ${ }^{b}$ Anit Parihara

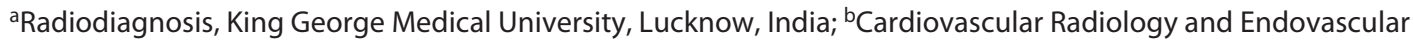 \\ Intervention, All India Institute of Medical Science, New Delhi, India
}

\section{Keywords}

Abdominal imaging · Gastrointestinal · Radiology · Computed tomography

\begin{abstract}
Objective: The objective of this systematic review was to evaluate key imaging manifestations of COVID-19 on abdominal imaging by utilizing a comprehensive review of the published literature.Method:A systematic literature search from PubMed, Google Scholar, and Scopus was performed for studies mentioning abdominal imaging findings in COVID-19 patients. Studies published from inception to 15 March 2021 were included. Results: A total of 116 studies comprising 1,198 patients were included. Abdominal pain was the most common indication for abdominal imaging in $50.2 \%$ of the patients. No abnormality was seen in $48.1 \%$ of abdominopelvic computed tomography scans. Segmental bowel wall thickening (14.7\%) was the most common imaging abnormality, followed by bowel ischemia (7.1\%), solid organ infarction (6.7\%), vessel thrombosis (6.7\%), and fluid-filled colon (6.2\%). Other relevant findings were dilated air-filled bowel, pancreatitis, pneumatosis/portal venous gas, bowel perforation, and appendicitis. Other than abdominal findings, COVID-19-related basal lung changes were incidentally detected in many studies. Moreover, the presence of bowel imaging findings was positively correlated with the clinical severity of COVID-19 infection. Conclusion: This review describes the abdominal imaging findings in COVID-19 patients. This is pertinent for the early diagnosis of COVID-19 in patients presenting solely with abdominal symptoms as well as in identifying abdominal complications in a known case of COVID-19.

(C) 2021 S. Karger AG, Basel
\end{abstract}

\section{Introduction}

In December 2019, there was an emergence of a cluster of an unidentified type of viral pneumonia in Wuhan city located in the Hubei province of China. The causative agent of this disease was later identified as a novel coronavirus which has $80 \%$ similarity with severe acute respiratory syndrome coronavirus (SARS-CoV) detected in 2013. This respiratory disease rapidly spread to other parts of China and then crossed international borders to spread in different parts of the world over a short period. The disease was later named COVID-19, and the causative virus was given the name SARS-CoV-2. On 11 March 2020, WHO declared it as a pandemic and COVID-19 emerged as a global health emergency. As of 2 May 2021, there were over 151 million cases of coronavirus worldwide with more than 3 million deaths reported globally [1].

The majority of patients of COVID-19 presented with fever and respiratory illness. But studies have shown that extrapulmonary symptoms like gastrointestinal (GI), neurological, cardiac, and renal symptoms are not uncommon in COVID-19 cases [2]. Amongst these, COVID-19 has a very high prevalence of GI symptoms. About $12 \%$ of COVID-19 patients reported GI symptoms during their course of illness, while fecal shedding was present in $41 \%$ of patients [3]. In another study on COVID-19, GI symptoms were as high as $50 \%$ which include symptoms like nausea (17.3\%), diarrhea (12.9\%), anorexia (12.2\%), abdominal pain (5.8\%), belching (5\%), and emesis (5\%) [4]. Abdominal and GI symptoms can also be the initial presentation of COVID-19 infection. 
Fig. 1. PRISMA 2009 flowchart describing selection of studies included in the systematic review.

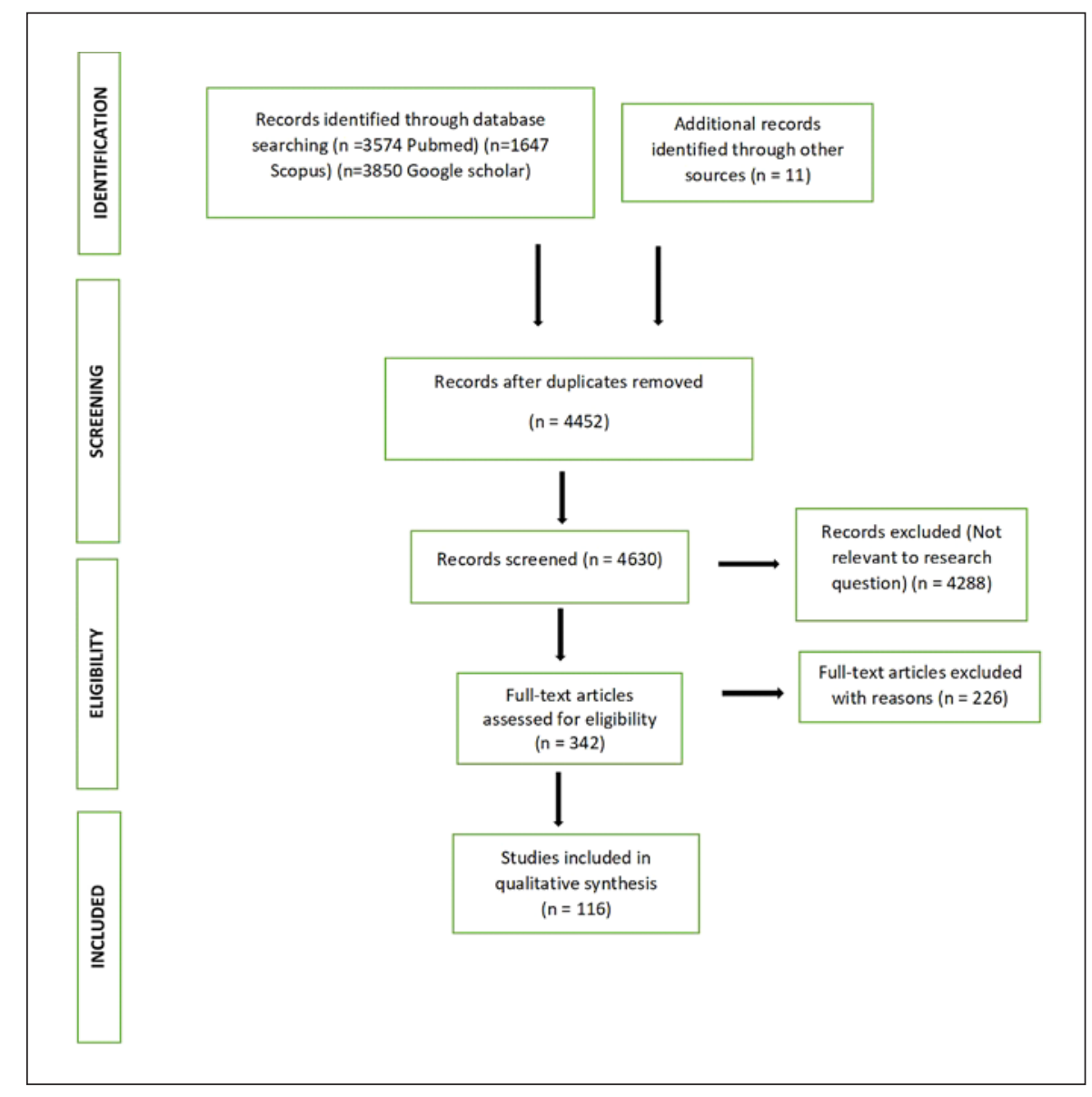

In such cases, there is more likelihood of missing the diagnosis. Radiological imaging may help in identifying some common imaging features which are more frequently seen or characteristic for COVID-19 patients. Thus, imaging can give a clue toward the possibility of COVID-19 infection in patients with abdominal symptoms. There are many studies in the current literature on the GI and abdominal symptoms in COVID-19 but very few of them have described the imaging findings in such cases. Despite limited available data, clinicians, especially radiologists must be aware of the common abdominal imaging findings in COVID-19 patients who present with abdominal symptoms. This systemic review will help in the early identification of COVID-19 patients with abdominal symptoms and predict the prognosis of the disease.

\section{Materials and Methods}

Search Strategy

Our search question was "What are the reported abdominal imaging findings in patients with COVID-19 infections?" An extensive electronic search of the published literature was done on 3 databases including PubMed, Google Scholar, and Scopus from its start till 15 march 2021. Keywords used for the search were coronavirus OR corona OR COVID-19 OR SARS-CoV-2 OR 2019nCoV OR n-CoV OR SARS-CoV-2 AND gastrointestinal OR abdominal OR intestine OR bowel OR colon OR renal OR kidney OR spleen OR liver OR pancreas OR adrenals OR gall bladder AND imaging OR diagnostic OR radiography OR ultrasound OR USG OR computed tomography OR CT scan OR magnetic resonance OR MRI. This search was first conducted on 16 March 2021 and the final update was done on 10 April 2021. Additionally, any potentially relevant studies on abdominal imaging in the reference list of shortlisted studies were also searched.

\section{Study Selection}

All the studies that mentioned abdominal imaging findings in patients having COVID-19 infection were selected. Only those patients were included in whom COVID-19 infection was confirmed on the RTPCR/antigen test either before or after the imaging. Those articles in which imaging findings were not described were excluded. No restriction on the language of the studies was kept. Only fully extractable studies were selected. Titles, keywords, abstract, or body of the manuscript was screened independently by 2 reviewers to shortlist the final articles according to the abovementioned criteria. All the duplicate studies were excluded. Disagreements were resolved by discussion and consensus between the reviewers. Search strategy and study selection (shown in Fig. 1) were done as described in the PRISMA statement [5]. The study was registered in the PRISMA trial - PROSPERO (CRD42020203384) [6]. 
Data Extraction and Quality Assessment

Data extraction was done by authors independently. An excel sheet database was maintained under different variables which include the study design, country, sample size, indication of imaging, imaging methods, imaging finding, normal imaging findings, clinical severity, and any important notes of cases. Finally, a narrative synthesis of the data was done using a Microsoft Excel sheet without meta-analysis. Additionally, a comparison between clinical severity and the presence of specific imaging findings was done, subject to the availability of clinical details in the studies. The methodology quality of studies was rated fair based on 9 items featured in the National Institute of Health quality assessment tool for case series studies [7].

\section{Results}

\section{Overview of the Included Studies}

A total of 4,452 articles were identified after an extensive search of the literature on all three databases and the removal of duplicates. Titles/abstracts of these articles were manually screened and finally 342 articles qualified for full-text review. After further scrutiny, a total of 116 articles in which abdominal imaging were done and met the inclusion criteria were included in the systematic review. Details of these studies are shown in Table 1 and online supplementary Table 1 (for all online suppl. material, see www.karger.com/doi/10.1159/000518473) [8-123]. Out of 116 studies included, 15 were retrospective studies with a sample size of 10 or more, 37 were case series (having less than 10 cases), and 64 were case reports. There is a scarcity of reporting of abdominal imaging findings in COVID-19 in the present literature due to which sample size in most of the included studies was small except in 7 studies where the sample size was $>50$. In these 116 studies, there were a total of 1,198 patients with 176 abdominal X-rays, $172 \mathrm{ab}-$ dominal ultrasonography, 949 abdominal computed tomography (CT)scans, and 6 magnetic resonance imaging done. Out of 1,198 patients, 72 were pediatric patients and 1,126 adults. Correlation of the presence of bowel imaging findings with clinical severity was done in 7 studies having a total of 473 adult patients.

\section{Indication for Abdominal Imaging}

The most common abdominal symptom for which abdominal imaging was done in COVID-19 patients was abdominal pain ( $50.2 \%$; 350 out of 697 patients) either alone or associated with other symptoms. Nausea and/or vomiting $(26 \% ; 186$ out of 697 patients) and diarrhea (25\%; 176 out of 697 patients) were among the other common symptoms. Imaging was done for suspicion of abdominal infection or sepsis in 40 patients (5.7\%) and abdominal bloating or distension in 39 patients (5.5\%). Other uncommon indications were GI bleed (21 patients; $3 \%$ ), bloody diarrhea (13 patients; $1 \%$ ), scrotal pain (3 patients), and oliguria ( 3 patients). Deranged liver function tests or raised amylase, lipase, or lactate were imaging indications in few studies. Eight patients were having acute ischemia of lower limbs for which abdominal and lower limb imaging were done. In most of the patients, abdominal symptoms were initial complaints, and in some, only presenting symptoms of COVID-19. While in the rest of the patients it developed subsequently during illness. Among pediatric patients, abdominal pain, vomiting, and diarrhea were common indications for abdominal imaging. Bloody diarrhea was seen in 7 pediatric patients.

In $501(41.8 \%)$ patients, indication for abdominal imaging was not described. In 2 retrospective studies by O'Shea et al. [8] and Dane et al. [9], abdominal imaging demonstrating the presence of thrombosis and ischemia was only included. In both these studies, indications for imaging were not described. A recent study by Tirumani et al. [10] compared abdominal imaging findings of COVID-19 in 34 patients who were not having any abdominal symptoms to 38 patients who were having abdominal symptoms. They found that two-thirds (61.5\%) of patients having bowel imaging findings were not having any abdominal symptoms. Also, abdominal findings were incidentally detected in upper abdominal cuts of chest CT in 5 patients of 3 different studies [10-12].

\section{Normal Abdominal Imaging Findings}

A total of 26 studies reported no concerning abnormality on abdominal imaging in 577 (48.1\%) patients (563 adults and 14 pediatric). Thus, 563 adults and 58 pediatric patients were having positive imaging studies. Among imaging studies, 154 (87.5\%) of abdominal Xrays, 73 (42\%) of ultrasonography, 437 (46\%) of abdomi$\mathrm{nal} \mathrm{CT}$, and $3(50 \%)$ of magnetic resonance imaging were normal. Of patients, $43 \%, 64 \%$, and $76 \%$ in 3 different large retrospective studies, respectively, have no abnormal abdominal imaging findings [13-15]. Another study by Tirumani et al. [10] showed that among 59 patients having normal imaging findings, 18 (31\%) patients were having abdominal symptoms. Additionally, many case series have shown the importance of lung base findings in detecting COVID-19 in otherwise normal abdominal scans $[14-22,30]$.

\section{Common Abdominal Imaging Findings in COVID-19}

Bowel Involvement

Among all the reviewed studies, the bowel was the most commonly involved organ, and bowel wall thickening with or without local inflammation was the most common imaging finding (83 patients; $14.7 \%$; shown in Table 2). Out of these, large bowel was involved in 28 , small bowel in 26, stomach in 6, esophagus in 2 , and the site was not mentioned in 23 patients.

Intestinal ischemia (40 patients; $7.1 \%$ ) was the second most common imaging finding. Imaging findings de- 
Table 1. Included studies and their demographic characters

\begin{tabular}{|c|c|c|c|}
\hline Study & Author & $\begin{array}{l}\text { Patients, } \\
n\end{array}$ & $\begin{array}{l}\text { Age, years } \\
\text { (mean/median/range) }\end{array}$ \\
\hline 1 & O’shea et al. [8] & 9 & $\mathrm{np}$ \\
\hline 2 & Dane et al. [9] & 80 & $58.8 \pm 14.5$ \\
\hline 3 & Tirumani et al. [10] & 72 & 62.2 \\
\hline 4 & Meini et al. [11] & 1 & 44 \\
\hline 5 & Le Berre et al. [12] & 1 & 71 \\
\hline 6 & Goldberg-Stein et al. [13] & 141 & $64 \pm 16$ \\
\hline 7 & Barkmeier et al. [14] & 43 & $64.5 \pm 17.3$ \\
\hline 8 & Funt et al. [15] & 338 & $19-80$ \\
\hline 9 & Abolyazid et al. [16] & 3 & $65,42,71$ \\
\hline 10 & Dane et al. [17] & 23 & $60.7 \pm 18.6$ \\
\hline 11 & Vu et al. [18] & 2 & 69,67 \\
\hline 12 & Sellevoll et al. [19] & 1 & $\mathrm{np}$ \\
\hline 13 & Siegel et al. [20] & 3 & 26,40 , and 50 \\
\hline 14 & Gahide et al. [21] & 3 & 65 \\
\hline 15 & Abdalhadi et al. [22] & 1 & 40 \\
\hline 16 & Blanco-Colino et al. [23] & 1 & 53 \\
\hline 17 & Khader et al. [24] & 1 & 40 \\
\hline 18 & Tang et al. [25] & 1 & 24 \\
\hline 19 & Kim et al. [26] & 1 & 42 \\
\hline 20 & Ibrahim et al. [27] & 2 & 33,33 \\
\hline 21 & Jaijakul et al. [28] & 1 & 56 \\
\hline 22 & Carvalho et al. [29] & 1 & 72 \\
\hline 23 & Voutsinas et al. [30] & 4 & $31,46,21$, and 27 \\
\hline 24 & Guo et al. [31] & 1 & 29 \\
\hline 25 & Hellinger et al. [32] & 1 & 62 \\
\hline 26 & Bhayana et al. [33] & 134 & $\mathrm{np}$ \\
\hline 27 & Sattar et al. [34] & 3 & $39,55,74$ \\
\hline 28 & Gartland et al. [35] & 1 & 47 \\
\hline 29 & De Nardi et al. [36] & 1 & 53 \\
\hline 30 & Almeida Vargas et al. [37] & 3 & 76,68, and 56 \\
\hline 31 & Seeliger et al. [38] & 5 & $64.4 \pm 18.7$ \\
\hline 32 & Giuffrè et al. [39] & 1 & 87 \\
\hline 33 & Saeed et al. [40] & 9 & Median-48 \\
\hline 34 & Łaski et al. [41] & 1 & 39 \\
\hline 35 & Poggiali et al. [42] & 10 & $50 \pm 18$ \\
\hline 36 & Ahmed et al. [43] & 3 & 42 \\
\hline 37 & Abdelmohsen et al. [44] & 30 & $20-74$ \\
\hline 38 & Collange et al. [45] & 1 & 56 \\
\hline 39 & Al Mahruqi et al. [46] & 2 & 51 \\
\hline 40 & Kielty et al. [47] & 1 & 47 \\
\hline 41 & Chan et al. [48] & 1 & 73 \\
\hline 42 & Cheung et al. [49] & 1 & 55 \\
\hline 43 & Norsa et al. [50] & 6 & 74 \\
\hline 44 & Ignat et al. [51] & 3 & $\mathrm{np}$ \\
\hline 45 & Beccara et al. [52] & 1 & 52 \\
\hline 46 & Thuluva et al. [53] & 1 & 29 \\
\hline 47 & Azouz et al. [54] & 1 & 56 \\
\hline 48 & Post et al. [55] & 2 & 56,58 \\
\hline 49 & Levolger et al. [56] & 2 & 50,58 \\
\hline 50 & Besutti et al. [57] & 3 & 60 \\
\hline 51 & Basara Akin et al. [58] & 1 & 48 \\
\hline 52 & Ahmed et al. [59] & 1 & 47 \\
\hline 53 & Vulliamy et al. [60] & 2 & 60,75 \\
\hline 54 & Carmo Filho et al. [61] & 1 & 33 \\
\hline 55 & Karki et al. [62] & 1 & 35 \\
\hline 56 & Woehl et al. [63] & 3 & 72 \\
\hline 57 & Gomez-Arbelaez [64] & 2 & 67,50 \\
\hline 58 & Mahan et al. [65] & 1 & 60 \\
\hline 59 & Santos Leite Pessoa et al. [66] & 2 & 57,53 \\
\hline
\end{tabular}


Table 1 (continued)

\begin{tabular}{|c|c|c|c|}
\hline Study & Author & $\begin{array}{l}\text { Patients, } \\
n\end{array}$ & $\begin{array}{l}\text { Age , years } \\
\text { (mean/median/range) }\end{array}$ \\
\hline 60 & de Barry et al. [67] & 1 & 79 \\
\hline 61 & La Mura et al. [68] & 1 & 72 \\
\hline 62 & Jafari et al. [69] & 1 & 26 \\
\hline 63 & Mohammadi et al. [70] & 1 & 26 \\
\hline 64 & Giacomelli et al. [71] & 1 & 67 \\
\hline 65 & Dhakal et al. [72] & 1 & 63 \\
\hline 66 & Anand et al. [73] & 1 & 59 \\
\hline 67 & Brikman et al. [74] & 1 & 61 \\
\hline 68 & Liu et al. [75] & 13 & 61 \\
\hline 69 & Aloysius et al. [76] & 1 & 36 \\
\hline 70 & Pinte et al. [77] & 1 & 47 \\
\hline 71 & Hadi et al. [78] & 1 & 47 \\
\hline 72 & Schreckenbach et al. [79] & 1 & 21 \\
\hline 73 & Kumaran et al. [80] & 1 & 64 \\
\hline 74 & Kataria et al. [81] & 1 & 49 \\
\hline 75 & Ghosh et al. [82] & 1 & 65 \\
\hline 76 & Purayil et al. [83] & 1 & 58 \\
\hline 77 & Shiralkar et al. [84] & 10 & $45.1 \pm 19.6$ \\
\hline 78 & Cheung et al. [85] & 1 & 38 \\
\hline 79 & AlHarmi et al. [86] & 1 & 52 \\
\hline 80 & Sandhu et al. [87] & 1 & 25 \\
\hline 81 & Alvis et al. [88] & 1 & 56 \\
\hline 82 & Schepis et al. [89] & 1 & 67 \\
\hline 83 & Hassani et al. [90] & 2 & 65,78 \\
\hline 84 & Kumar et al. [91] & 1 & 70 \\
\hline 85 & Frankel et al. [92] & 1 & 66 \\
\hline 86 & Peleg et al. [93] & 1 & 46 \\
\hline 87 & La Marca et al. [94] & 1 & 43 \\
\hline 88 & Bruni et al. [95] & 1 & 59 \\
\hline 89 & Balaphas et al. [96] & 2 & 84 \\
\hline 90 & Mattone et al. [97] & 1 & 66 \\
\hline 91 & Suwanwongse et al. [98] & 1 & 18 \\
\hline 92 & Meireles et al. [99] & 1 & 36 \\
\hline 93 & Guotao et al. [100] & 1 & 85 \\
\hline 94 & Walpole et al. [101] & 1 & 33 \\
\hline 95 & Aiello et al. [102] & 1 & 73 \\
\hline 96 & Wong et al. [103] & 9 & $54.3(35-65)$ \\
\hline 97 & Lakshmanan et al. [104] & 1 & 72 \\
\hline 98 & Pérez Naranjo et al. [105] & 1 & 42 \\
\hline 99 & Horvat et al. [106] & 81 & $61(25-92)$ \\
\hline 100 & Sahn et al. [107] & 19 pediatric & $2.2-19$ \\
\hline 101 & Miller et al. [108] & 15 pediatric & 7 months -20 years \\
\hline 102 & Blumfeld et al. [109] & 16 pediatric & 20 months -20 years \\
\hline 103 & Tullie et al. [110] & 5 pediatric & $4,8,11,12$, and 14 \\
\hline 104 & Cabrero-Hernández et al. [111] & 2 pediatric & 9,11 \\
\hline 105 & Riphagen et al. [112] & 1 pediatric & 14 \\
\hline 106 & Rohani et al. [113] & 1 pediatric & 6.5 months \\
\hline 107 & Makrinioti et al. [114] & 2 pediatric & 10 months \\
\hline 108 & Athamnah et al. [115] & 1 pediatric & 2.5 months \\
\hline 109 & Martínez-Castaño et al. [116] & 1 pediatric & 6 months \\
\hline 110 & Moazzam et al. [117] & 1 pediatric & 4 months \\
\hline 111 & Rajalakshmi et al. [118] & 1 pediatric & 8 months \\
\hline 112 & Bazuaye-Ekwuyasi et al. [119] & 1 pediatric & 9 months \\
\hline 113 & Harwood et al. [120] & 1 pediatric & 3 \\
\hline 114 & Samies et al. [121] & 3 pediatric & 11,16 , and 15 \\
\hline 115 & Gagliardi [122] & 1 pediatric & 14 \\
\hline 116 & Mehl et al. [123] & 1 pediatric & 7 weeks \\
\hline
\end{tabular}


Table 2. Incidence of common abdominal imaging findings in COVID-19 patients

\begin{tabular}{ll}
\hline Common imaging findings & Incidence: patients, \\
& $N(\%=N / 563)$ \\
\hline Bowel, $n$ (\%) & \\
$\quad$ Bowel wall thickening & $83(14.7)$ \\
Intestinal ischemia & $40(7.1)$ \\
Fluid-filled bowel or colon & $35(6.2)$ \\
Dilated air-filled bowel & $33(5.8)$ \\
Pneumatosis of the bowel wall & $25(4.4)$ \\
Perforation with pneumoperitoneum & $9(1.6)$ \\
Acute appendicitis & $7(1.2)$ \\
GI bleed & $6(1)$ \\
Solid visceral organ, $n$ (\%) & $38(6.7)$ \\
Solid organ infarcts & $29(5.1)$ \\
Acute pancreatitis & $36(6.3)$ \\
Others & $38(6.7)$ \\
Vascular thrombosis & \\
Gall bladder and biliary system, $n(\%)$ & $24(4.2)$ \\
$\quad$ Gall bladder sludge & $12(2.2)$ \\
Acute cholecystitis & $7(1.2)$ \\
Gall bladder wall thickening & $5(0.8)$ \\
Gall bladder distention & $8(1.5)$ \\
Bile duct dilatation & $23 \%$ \\
Nonspecific findings/others & incidence: patients, \\
\hline Pediatric patients & $N(\%=N / 58)$ \\
& $20(34)$ \\
\hline Bowel wall thickening & $13(22)$ \\
Mesenteric lymphadenopathy & $13(22)$ \\
Ascites & $10(17)$ \\
Signs of acalculous cholecystitis & \\
\hline & \\
\hline &
\end{tabular}

GI, gastrointestinal.

scribed in intestinal ischemia on CT scan were bowel wall thickening or thinning, hyperenhancement or severe hypoenhancement-associated mesenteric intravenous air, bowel wall air, free air in the peritoneum, and portal venous gas. An associated mesenteric vein thrombus (3 patients) and superior mesenteric artery thrombus ( 3 patients) were also present in a few of them. A fluid-filled bowel or colon was the third common (35 patients; $6.2 \%$ ) imaging manifestation.

Dilated air-filled bowel was seen in 33 patients (5.8\%) and perforation with pneumoperitoneum in 9 patients (1.6\%). Pneumatosis of the bowel wall was seen in 25 patients (4.4\%) associated with portal venous gas in some of them. Three patients had associated bowel wall thickening. Acute appendicitis and GI bleed were seen in 7 patients $(1.2 \%)$ and 6 patients (1\%), respectively. Few other uncommon findings were colonic diverticulosis $(7 \mathrm{pa}-$ tients; $1.2 \%$ ), mesenteric or peri-intestinal stranding (4 patients; $0.7 \%$ ), and epiploic appendicitis (1 patient; $0.1 \%)$.

\section{Correlation of Bowel Imaging Findings with Disease}

\section{Severity}

We also studied the association between the presence of bowel abnormalities on imaging with the frequency of ICU admission, intubation, death, and length of hospitalization or ICU stay. Due to heterogeneity of data and lack of clinical details, only 7 studies (total 473 patients) qualified for this comparison, and most of the case reports and case series were excluded. The presence of bowel findings on imaging studies was positively correlated with clinical severity, indirectly assessed by ICU admission (66 vs. $34 \%$ ), intubation (36 vs. $19 \%$ ), death (26 vs. $14 \%$ ), and length of hospitalization (17.3 vs. 14.6 days) or ICU stay (10.8 vs. 7.3 days; shown in Table 3 ).

\section{Solid Visceral Organ Involvement}

Infarction was the most common imaging finding in solid visceral organs. Out of the total of 38 patients $(6.7 \%)$ with solid organ infarcts, the spleen was the most commonly involved (17 patients), followed by either of the kidneys (16 patients). For the other 5 infarcts, an organ is not specified.

Imaging findings of acute pancreatitis were seen in 29 patients (5.1\%). Out of these, 3 patients also had main pancreatic duct dilatation.

Other less common imaging findings (6.3\%) included hepatomegaly (4 patients), pyelonephritis (11 patients), nonspecific renal stranding (8 patients), splenomegaly (2 patients), hepatitis (2 patients), echogenic kidneys (3 patients), heterogenous liver (2 patients), and enlarged kidneys (2 patients). Bilateral adrenal involvement was seen as infarction and hemorrhage, 1 patient of each ( 2 patients).

\section{Vascular Thrombosis}

Vascular thrombosis including both arterial and venous thrombi was diagnosed in a total of 38 patients $(6.7 \%)$. Acute thrombus in the abdominal aorta was seen on CT in 15 patients. Two of these patients had associated splenic artery thrombosis with splenic infarction, and another patient had a thrombus in the renal artery. Thrombus extension into the celiac and internal iliac artery was also seen, one case of each. Superior mesenteric artery thrombus was seen in 8 patients and isolated internal iliac artery thrombus in 1 . There was one case report (1 patient; $0.2 \%$ ) describing infrarenal aortitis with focal dissection [69]. Venous thrombosis was seen involving superior mesenteric vein (4 patients), portal vein (4 patients), inferior mesenteric vein (1 patient), renal vein (2 patients), inferior vena cava (2 patients), and ovarian vein in pregnant women (1 patient).

\section{Gall Bladder and Biliary System}

Gall bladder sludge (24 patients on ultrasound; $4.2 \%$ ) was the most common imaging finding in COVID-19 pa- 
Table 3. Comparison of presence or absence of bowel imaging findings in COVID-19 patients with clinical severity

\begin{tabular}{|c|c|c|c|c|c|c|c|c|}
\hline $\begin{array}{l}\text { Bowel abnormality (present - p; } \\
\text { absent }-\mathrm{n} \text { ) correlation with } \\
\text { clinical severity }\end{array}$ & $\begin{array}{l}\text { Tirumani et al. } \\
{[10](N)}\end{array}$ & $\begin{array}{l}\text { Horvat et al. } \\
{[106](N)}\end{array}$ & $\begin{array}{l}\text { Bhayana et al. } \\
{[33](N)}\end{array}$ & $\begin{array}{l}\text { Goldberg-Stein } \\
\text { et al. [13] }(N)\end{array}$ & $\begin{array}{l}\text { Abdelmohsen } \\
\text { et al. [44] }(N)\end{array}$ & $\begin{array}{l}\text { Wong et al. } \\
{[103](N)}\end{array}$ & $\begin{array}{l}\text { Norsa et al. } \\
{[50](N)}\end{array}$ & $\begin{array}{l}\text { Pooled } \\
\text { proportion } \\
(\%)\end{array}$ \\
\hline$P$ with ICU & & $10 / 20$ & $23 / 31$ & & $21 / 30$ & & & $54 / 81(66)$ \\
\hline$N$ with ICU & & $21 / 61$ & & & & & & $21 / 61(34)$ \\
\hline$P$ with intubation & $5 / 13$ & $7 / 20$ & & & & & & $12 / 33(36)$ \\
\hline$N$ with intubation & $16 / 59$ & $7 / 61$ & & & & & & $\begin{array}{l}23 / 120 \\
(19)\end{array}$ \\
\hline$P$ with death & $3 / 13$ & $9 / 20$ & & $10 / 80$ & & $7 / 9$ & $4 / 6$ & $\begin{array}{l}33 / 128 \\
(26)\end{array}$ \\
\hline$N$ with death & $6 / 59$ & $14 / 61$ & & $5 / 61$ & & & & $\begin{array}{l}25 / 181 \\
(14)\end{array}$ \\
\hline$P$ with mean ICU stays, days & 6.4 & 13.7 & & & & & & 10.8 \\
\hline$N$ with mean ICU stays, days & 7 & 7.6 & & & & & & 7.3 \\
\hline$P$ with mean hospital stays, days & 13.2 & 20.1 & & & & & & 17.3 \\
\hline$N$ with mean hospital stays, days & 14.0 & 15.2 & & & & & & 14.6 \\
\hline
\end{tabular}

tients, followed by acute cholecystitis (12 patients; $2.2 \%$ ), gall bladder wall thickening (7 patients; $1.2 \%$ ), and gall bladder distention ( 5 patients; $0.8 \%$ ). Bile duct dilatation was seen in 8 patients (1.5\%).

\section{Other Nonspecific Imaging Findings}

Nonspecific findings detected on abdominal imaging (12\%) include urinary bladder thickening/cystitis (36 patients), ascites (15 patients), retroperitoneal lymphadenopathy (4 patients), mesenteric lymphadenopathy (4 patients), retroperitoneal hematoma (1 patient), infiltration of retroperitoneal fat ( 3 patients), epididymitis ( 1 patient), adnexal torsion (2 patients), and hydrosalpinx (2 patients). These findings were likely incidental and not directly related to COVID-19 infection.

Abdominal Imaging Findings in Pediatric Patients

Among pediatric patients ( 72 patients), inflammatory bowel wall thickening (20 patients; $34 \%$ ) was the most common finding, predominantly involving the ileum and ileocecal region (12 patients). Mesenteric lymphadenopathy (13 patients; $22 \%$ ), ascites (13 patients; $22 \%$ ), and signs of acalculous cholecystitis like gall bladder edema, biliary dilatation, and biliary sludge (10 patients; $17.2 \%$ ) were also seen in a subset of COVID-19 patients. Other less common imaging findings included intussusception (7 patients), hepatomegaly (6 patients), echogenic kidneys ( 5 patients), dilated bowel (5 patients), appendicitis ( 2 patients), acute pancreatitis ( 2 patients), pneumatosis ( 2 patients), splenomegaly (1 patient), and orchi-epididymitis (1 patient) [107-123]. Bowel wall thickening and ascites were the most common imaging findings in pediatric patients having multiple inflammatory syndromes [107-109].

\section{Discussion}

SARS-CoV-2 virus invades the alveolar epithelial cells by binding to angiotensin-converting enzyme 2 (ACE 2) receptors [124]. These receptors are also found on enterocytes, vascular endothelial cells, the pancreas, kidneys, adrenals, biliary tree, and testis. Such ACE-2 receptors may be responsible for the direct entry of this virus into these organs leading to local pathological reaction and therefore abnormal imaging findings. This is supported by the detection of the SARS-CoV-2 virus in feces samples and samples from a pancreatic pseudocyst $[29,89$, 125]. One case report also mentioned the presence of viral RNA in the gallbladder wall in a patient with acute acalculous cholecystitis [96]. Marked pro-inflammatory response in COVID-19 infection causes the release of cytokines with activation of the coagulation cascade [126, 127]. This leads to a prothrombotic state with an increased risk of thrombus formation at multiple sites. These serial changes explain vascular thrombosis, bowel ischemia, and solid organ infarction.

This review describes the key abdominal imaging features in COVID-19 after compiling the data from the published literature. The data demonstrated abdominal pain to be the most common indication for abdominal imaging, accounting for the majority of CT scans. Around $48.1 \%$ of abdominopelvic CT scans were normal with no reported abnormalities. Therefore, negative abdominal scans are not uncommon in COVID-19 patients. However, in COVID-19 patients who present only with abdominal symptoms, these scans may incidentally detect changes of SARS-CoV-2 pneumonia at the lung bases as a hint of this infection [14-22, 30].

As per the review, bowel involvement was most frequently detected on abdominal imaging in COVID-19 
patients with segmental wall thickening commonest reported finding. This is in agreement with 2 large retrospective studies by Funt et al. [15] and Bhayana et al. [33], where bowel wall thickening was the predominant finding seen in $28.8 \%$ and $31 \%$ patients, respectively. Intestinal ischemia was the second most common finding as described in multiple case reports. Many studies have demonstrated intestinal pneumatosis and proposed ischemia to be the cause [33,37, 102-105]. Although fluid-filled bowel was the most common bowel imaging finding in 2 large studies by Tirumani et al. [10] and Bhayana et al. [33], in our review it was the third most common bowel imaging finding. The possible reason for such difference could be underreporting of this finding.

After pooled analysis, frequency of ICU admission, intubation, death, and length of hospitalization/ICU admission were positively correlated with the presence of bowel abnormalities in this study. The presence of bowel involvement was also positively correlated with ICU admission in a study by Bhayana et al. [33] However, no such correlation was obtained in the study by Tirumani et al. [10], where they explained that systemic hypoperfusion and systemic coagulopathy seen in ICU patients, unrelated to the direct effect of covid infection could be the cause of ischemic and bowel-related changes seen on imaging. Although, a recent study with a sample size of 486 patients found a higher rate of GI complications, including mesenteric ischemia, in critically ill patients with $\mathrm{CO}$ VID-19 compared with propensity score-matched patients without COVID-19 [128]. These findings suggest that there is a higher risk of bowel abnormalities in critically ill patients and those with bowel findings on imaging have a higher chance of poor prognosis and increased clinical severity.

After GI tract abnormality, solid visceral organ infarction and vessel thrombosis were the second most common abnormality. Multiple case reports and few large case series demonstrated thrombus in major abdominal arteries and veins confirming the presence of hypercoagulability in COVID-19 infection [8, 9]. Acute pancreatitis was a common imaging finding in COVID-19 infection both in the adult and adolescent age-groups. Gall bladder and biliary findings were also reported, mostly on ultrasound. Apart from inflammatory bowel wall thickening, mesenteric lymphadenopathy and ascites were commonly reported in the pediatric age-group.

A study by Barkmeier et al. [14], which evaluated 43 abdominal CT concluded that positive abdominal findings in their study were not different from their pre-pandemic abdominal findings evaluated for abdominal pain, and the role of abdominal CT in COVID-19 was only to identify characteristic pulmonary findings if present at the lung bases. In contrast, another study by Funt et al. [15] which compared abdominal imaging findings of 338
COVID-19 positive patients with that of 259 COVID-19 negative patients. They found out that abdominal pathology was less frequent in COVID-19 positive patients as compared to negative patients (70.1 vs. $52.2 \%)$; however, when abdominal findings were present, COVID-19 positive patients had a higher rate of imaging findings suggestive of inflammation of organs with high expression of ACE-2 receptor (58 vs. 29.8\%) [15]. Therefore, the causal relationship between COVID-19 infection and occurrence of abdominal imaging findings has not been fully established and needs further research. Our study determines the correlation between COVID-19 and organ involvement of disease; however, the extent to which factors like comorbidities, the severity of illness, and treatment administered influence the imaging findings were not determined.

Our review highlights the common imaging findings in the abdomen of COVID-19 patients. The presence of these common imaging findings should alarm the radiologist and clinicians to raise the possibility of COVID-19 infection or its complications. The presence of imaging findings, especially bowel abnormalities predict poorer prognosis and increased clinical severity of COVID-19 infection. Thus, imaging should not be delayed in COVID-19 patients presenting with abdominal symptoms. The presence of bowel ischemia, solid organ infarction, and other thromboembolic phenomena on imaging can guide in making important clinical decisions regarding anticoagulation treatment or catheter-directed thrombolysis.

Like others, this review also has some limitations. Due to the broad scope of this review, some of the imaging features may have been missed. Few relevant studies might have been missed due to the nonutilization of other search databases. The experience and expertise of different interpreting radiologists in studies may induce variability in imaging findings. Studies were heterogeneous in terms of sample size, inclusion, exclusion criteria, and methodology, which may introduce variability in imaging findings among studies. Additionally, due to the lack of comparison groups in most studies, findings on imaging, especially fewer common ones can be coincidental and not related to COVID-19. The severity of the disease, treatment administered, and time at which imaging was done are the factors that may influence the imaging findings. These factors were not considered in our study.

\section{Conclusion}

GI tract abnormality is the most common imaging finding on abdominal imaging. Nonspecific segmental bowel wall thickening, followed by ischemic bowel chang- 
es and fluid-filled colon were the predominant bowel changes. Solid organ infarction, vascular thrombosis, and pancreatitis were not uncommon in patients of COVID-19. The presence of bowel abnormality on imaging was associated with increased clinical severity and poor prognosis of disease. Knowledge of these imaging features will help in considering a diagnosis of COVID-19, identifying its complications, and predicting clinical severity in an appropriate clinical setting.

\section{Acknowledgments}

We would like to thank Mr. P.B. Singh and Mrs. Manju Singh for managing all the data-related work.

\section{Statement of Ethics}

An ethics statement was not required for this study type, no human or animal subjects or materials were used. PROSPERO registration was obtained. Registration number is CRD42020203384.

\section{Conflict of Interest Statement}

The authors have no conflicts of interest to declare.

\section{Funding Sources}

The authors state that this work has not received any funding.

\section{Author Contributions}

Priya Singh and Surya Pratap Singh had done the literature search. The manuscript was written by Priya Singh. Manuscript review was done by Amit Kumar Verma, Sreenivasa Narayana Raju, and Surya Pratap Singh. Final revision of the study was done by Anit Parihar.

\section{Data Availability Statement}

All data generated or analyzed during this study are included in this article reference list and online suppl. file. Further enquiries can be directed to the corresponding author.

\section{References}

1 World Health Organization. WHO Coronavirus Disease (COVID-19) Dashboard. Available from: https://covid19.who.int/. Accessed 2021 May 3.

2 Gupta A, Madhavan MV, Sehgal K, Nair N, Mahajan S, Sehrawat TS, et al. Extrapulmonary manifestations of COVID-19. Nat Med. 2020;26(7):1017-32.

3 Parasa S, Desai M, Thoguluva Chandrasekar V, Patel HK, Kennedy KF, Roesch T, et al. Prevalence of gastrointestinal symptoms and fecal viral shedding in patients with coronavirus disease 2019: a systematic review and meta-analysis. JAMA Netw Open. 2020;3(6): e2011335.

4 Zhang J, Dong X, Cao Y, Yuan Y, Yang Y, Yan $\mathrm{Y}$, et al. Clinical characteristics of 140 patients infected with SARS-CoV-2 in Wuhan, China. Allergy. 2020;75(7):1730-41.

5 PRISMA [Internet]; 2021. Available from: http://prisma-statement.org Accessed 2021 May 12.

6 Augustus C. Long Health Sciences Library. PROSPERO: a registry for systematic review protocols [Internet]. 2021. Available from: https: //library.cumc.columbia.edu/insight/ prospero-registry-systematic-review-protocols Accessed 2021 May 12.

7 National Heart, Lung, and Blood Institute (NHLBI). Study quality assessment tools. [cited 2021 May 1]. Available from: https://www. nhlbi.nih.gov/health-topics/study-qualityassessment-tools.

8 O'Shea A, Parakh A, Hedgire S, Lee SI. Multisystem assessment of the imaging manifestations of coagulopathy in hospitalized patients with coronavirus disease (COVID-19). AJR Am J Roentgenol. 2021;216(4):1088-98.
9 Dane B, Smereka P, Wain R, Kim D, S Katz D. Hypercoagulability in patients with coronavirus disease (COVID-19): identification of arterial and venous thromboembolism in the abdomen, pelvis, and lower extremities. AJR Am J Roentgenol. 2021;216(1):104-5.

10 Tirumani S, Rahnemai-azar A, Pierce J, Parikh K, Martin S, Gilkeson R, et al. Are asymptomatic gastrointestinal findings on imaging more common in COVID-19 infection? Study to determine frequency of abdominal findings of COVID-19 infection in patients with and without abdominal symptoms and in patients with chest-only CT scans. Abdom Radiol. 2021;46(6):2407-14.

11 Meini S, Zini C, Passaleva MT, Frullini A, Fusco F, Carpi R, et al. Pneumatosis intestinalis in COVID-19. BMJ Open Gastroenterol. 2020;7(1):e000434.

12 Le Berre A, Marteau V, Emmerich J, Zins M. Concomitant acute aortic thrombosis and pulmonary embolism complicating COVID-19 pneumonia. Diagn Interv Imaging. 2020;101(5):321-2.

13 Goldberg-Stein S, Fink A, Paroder V, Kobi M, Yee J, Chernyak V. Abdominopelvic CT findings in patients with novel coronavirus disease 2019 (COVID-19). Abdom Radiol. 2020; 45(9):2613-23.

14 Barkmeier DT, Stein EB, Bojicic K, Otemuyiwa B, Vummidi D, Chughtai A, et al. Abdominal CT in COVID-19 patients: incidence, indications, and findings. Abdom Radiol. 2020; 46(3):1256-62.

15 Funt SA, Cohen SL, Wang JJ, Sanelli PC, Barish MA. Abdominal pelvic CT findings compared between COVID-19 positive and COVID-19 negative patients in the emergency department setting. Abdom Radiol (NY). 2020;46(4):1498-505.
16 Abolyazid S, Alshareef S, Abdullah N, Khalil A, Hamza N, Salem A. COVID-19 pneumonia identified by CT of the abdomen: a report of three emergency patients presenting with abdominal pain. Radiol Case Rep. 2020; 15(11):2090-4.

17 Dane B, Brusca-Augello G, Kim D, Katz DS Unexpected findings of coronavirus disease (COVID-19) at the lung bases on abdominopelvic CT. AJR Am J Roentgenol. 2020;215(3): 603-6.

18 Vu D, Ruggiero M, Choi WS, Masri D, Flyer M, Shyknevsky I, et al. Three unsuspected CT diagnoses of COVID-19. Emerg Radiol. 2020; 27(3):229-32.

19 Sellevoll H, Saeed U, Young V, Sandbæk G, Gundersen K, Mala T. Covid-19 med akutte magesmerter som debutsymptom. Tidsskrift Den Norske Legeforening. 2020.

20 Siegel A, Chang PJ, Jarou ZJ, Paushter DM, Harmath CB, Arevalo JB, et al. Lung base findings of coronavirus disease (COVID-19) on abdominal CT in patients with predominant gastrointestinal symptoms. AJR Am J Roentgenol. 2020;215(3):607-9.

21 Gahide G, Frandon J, Vendrell JF. COVID-19 patients presenting with afebrile acute $a b$ dominal pain. Clin Med (Lond). 2020;20(3): e4-6.

22 Abdalhadi A, Alkhatib M, Mismar AY, Awouda W, Albarqouni L. Can COVID 19 present like appendicitis? IDCases. 2020;21: e00860.

23 Blanco-Colino R, Vilallonga R, Martín R, Petrola C, Armengol M. Suspected acute abdomen as an extrapulmonary manifestation of Covid-19 infection. Cir Esp (Eng Ed). 2020; 98(5):295-6. 
24 Khader M, Al Bishawi A, Kambal A, Abdelmajid A. SARS-CoV-2 infection presenting as colitis with chest and abdomen CT findings. Radiol Case Rep. 2020;15(11):2427-32.

25 Tang L, Cheng X, Tian C, Wang R, Zhou H, $\mathrm{Wu}$ W, et al. Computed tomography (CT) intestinal alterations of coronavirus disease 2019 (COVID-19) from the imaging perspective: a case description. Quant Imaging Med Surg. 2020;10(5):1145-9.

26 Kim J, Thomsen T, Sell N, Goldsmith AJ. Abdominal and testicular pain: an atypical presentation of COVID-19. Am J Emerg Med. 2020;38(7):1542-e3.

27 Ibrahim YS, Karuppasamy G, Parambil JV, Alsoub H, Al-Shokri SD. Case report: paralytic ileus: a potential extrapulmonary manifestation of severe COVID-19. Am J Trop Med Hyg. 2020;103(4):1600-3.

28 Jaijakul S. Colitis as a sole presentation of SARS-CoV-2 infection: case report. SN Compr Clin Med. 2020;2(7):1-3.

29 Carvalho A, Alqusairi R, Adams A, Paul M, Kothari N, Peters S, et al. SARS-CoV-2 gastrointestinal infection causing hemorrhagic colitis: implications for detection and transmission of COVID-19 disease. Am J Gastroenterol. 2020;115(6):942-6.

30 Voutsinas N, Toussie D, Jacobi A, Bernheim A, Chung M. Incidental CT findings in the lungs in COVID-19 patients presenting with abdominal pain. Clin Imaging. 2020;67:1-4.

31 Guo Y, Hu X, Yu F, Chen J, Zheng W, Liu J, et al. Abdomen CT findings in a COVID-19 patient with intestinal symptoms and possibly false negative RT-PCR before initial discharge. Quant Imaging Med Surg. 2020;10(5): 1158-61.

32 Hellinger JC, Sirous R, Hellinger RL, Krauthamer A. Abdominal presentation of COVID-19. Appl Radiol. 2020;49(3):24-6.

33 Bhayana R, Som A, Li MD, Carey DE, Anderson MA, Blake MA, et al. Abdominal imaging findings in COVID-19: preliminary observations. Radiology. 2020;297(1):E207-15.

34 Sattar Y, Connerney M, Rauf H, Saini M, Ullah W, Mamtani S, et al. Three cases of COVID-19 disease with colonic manifestations. Am J Gastroenterol. 2020;115(6):948-50.

35 Gartland RM, Velmahos GC. Bowel necrosis in the setting of COVID-19. J Gastrointest Surg. 2020;24(12):2888-9.

36 De Nardi P, Parolini DC, Ripa M, Racca S, Rosati R. Bowel perforation in a COVID-19 patient: case report. Int J Colorectal Dis. 2020; 35(9):1797-800.

37 Almeida Vargas A, Valentí V, Sánchez Justicia C, Martínez Regueira F, Martí Cruchaga P, Luján Colás J, et al. Severe colon ischemia in patients with severe coronavirus-19 (COVID-19). Rev Esp Enferm Dig. 2020;112:784.

38 Seeliger B, Philouze G, Cherkaoui Z, Felli E, Mutter D, Pessaux P. Acute abdomen in patients with SARS-CoV-2 infection or co-infection. Langenbecks Arch Surg. 2020;405(6): 861-6.

39 Giuffrè M, Bozzato AM, Di Bella S, Occhipinti AA, Martingano P, Cavallaro MFM, et al. Spontaneous rectal perforation in a patient with SARS-CoV-2 infection. J Pers Med. 2020;10(4):157.
40 Saeed U, Sellevoll HB, Young VS, Sandbaek G, Glomsaker T, Mala T. COVID-19 may present with acute abdominal pain. Br J Surg. 2020;107(7):e186-7.

41 Łaski D, Biernat K, Kaska Ł. Pneumatosis intestinalis due to COVID-19 infection in kidney transplant recipient: a case report. Transplant Proc. 2021.

42 Poggiali E, Ramos PM, Bastoni D, Vercelli A, Magnacavallo A. Abdominal pain: a real challenge in novel COVID-19 infection. Eur J Case Rep Intern Med. 2020;7(4):001632.

43 Ahmed AOE, Badawi M, Ahmed K, Mohamed MFH. Case report: COVID-19 masquerading as an acute surgical abdomen. Am J Trop Med Hyg. 2020;103(2):841-3.

44 Abdelmohsen MA, Alkandari BM, Gupta VK, Elsebaie N. Gastrointestinal tract imaging findings in confirmed COVID-19 patients: a non-comparative observational study. Egypt J Radiol Nucl Med. 2021;52(1).

45 Collange O, Tacquard C, Delabranche X, Leonard-Lorant I, Ohana M, Onea M, et al. Coronavirus disease 2019: associated multiple organ damage. Open Forum Infect Dis. 2020;7(7):ofaa249.

46 Al Mahruqi G, Stephen E, Abdelhedy I, Al Wahaibi K. Our early experience with mesenteric ischemia in COVID-19 positive patients. Ann Vasc Surg. 2021;73:129-132.

47 Kielty J, Duggan WP, O’Dwyer M. Extensive pneumatosis intestinalis and portal venous gas mimicking mesenteric ischaemia in a patient with SARS-CoV-2. Ann R Coll Surg Engl. 2020;102(6):e145-7.

48 Chan KH, Lim SL, Damati A, Maruboyina SP, Bondili L, Abu Hanoud A, et al. Coronavirus disease 2019 (COVID-19) and ischemic colitis: an under-recognized complication. Am J Emerg Med. 2020;38(12):2758.e1-2758.e4.

49 Cheung S, Quiwa JC, Pillai A, Onwu C, Tharayil ZJ, Gupta R. Superior mesenteric artery thrombosis and acute intestinal ischemia as a consequence of COVID-19 Infection. Am J Case Rep. 2020;21:e925753.

50 Norsa L, Bonaffini PA, Indriolo A, Valle C, Sonzogni A, Sironi S. Poor outcome of intestinal ischemic manifestations of COVID-19. Gastroenterology. 2020;159(4):1595.e1.

51 Ignat M, Philouze G, Aussenac-Belle L, Faucher V, Collange O, Mutter D, et al. Small bowel ischemia and SARS-CoV-2 infection: an underdiagnosed distinct clinical entity. Surgery. 2020;168(1):14-6.

52 Beccara LA, Pacioni C, Ponton S, Francavilla S, Cuzzoli A. Arterial mesenteric thrombosis as a complication of SARS-CoV-2 infection. Eur J Case Rep Intern Med. 2020;7(5):001690.

53 Thuluva S, Zhu H, Tan M, Gupta S, Yeong K, Cheong Wah S, et al. A 29-year-old male construction worker from india who presented with left- sided abdominal pain due to isolated superior mesenteric vein thrombosis associated with SARS-CoV-2 infection. Am J Case Rep. 2020;21:e926785.

54 Azouz E, Yang S, Monnier-Cholley L, Arrivé L. Systemic arterial thrombosis and acute mesenteric ischemia in a patient with COVID-19. Intensive Care Med. 2020;46(7):14645 .
55 Post A, den Deurwaarder ESG, Bakker SJL, de Haas RJ, van Meurs M, Gansevoort RT, et al. Kidney infarction in patients with COVID-19. Am J Kidney Dis. 2020;76(3):431-5.

56 Levolger S, Bokkers RPH, Wille J, Kropman RHJ, de Vries JPM. Arterial thrombotic complications in COVID-19 patients. J Vasc Surg Cases Innov Tech. 2020;6(3):454-9.

57 Besutti G, Bonacini R, Iotti V, Marini G, Riva $\mathrm{N}$, Dolci $\mathrm{G}$, et al. Abdominal visceral infarction in 3 patients with COVID-19. Emerg Infect Dis. 2020;26(8):1926-8.

58 Basara Akin I, Altay C, Eren Kutsoylu O, Secil M. Possible radiologic renal signs of COVID-19. Abdom Radiol. 2020;46(2):692-5.

59 Ahmed AOE, Mohamed SF, Saleh AO, AlShokri SD, Ahmed K, Mohamed MFH. Acute abdomen -like-presentation associated with SARS-CoV-2 infection. IDCases. 2020;21: e00895.

60 Vulliamy P, Jacob S, Davenport RA. Acute aorto-iliac and mesenteric arterial thromboses as presenting features of COVID-19. Br J Haematol. 2020;189(6):1053-4.

61 Carmo Filho A, Cunha BDS. Inferior mesenteric vein thrombosis and COVID-19. Rev Soc Bras Med Trop. 2020;53:e20200412.

62 Karki S, Rawal SB, Malla S, Rayamajhi J, Thapa BB. A case report on spontaneous hemoperitoneum in COVID-19 patient. Int J Surg Case Rep. 2020;75:211-3.

63 Woehl B, Lawson B, Jambert L, Tousch J, Ghassani A, Hamade A. 4 cases of aortic thrombosis in patients with COVID-19. JACC Case Rep. 2020;2(9):1397-401.

64 Gomez-Arbelaez D, Ibarra-Sanchez G, Garcia-Gutierrez A, Comanges-Yeboles A, Ansuategui-Vicente $M$, Gonzalez-Fajardo JA. COVID-19-related aortic thrombosis: a report of four cases. Ann Vasc Surg. 2020;67: 10-3.

65 Mahan K, Kabrhel C, Goldsmith AJ. Abdominal pain in a patient with COVID-19 infection: a case of multiple thromboemboli. Am J Emerg Med. 2020;38(10):2245-e5.

66 Santos Leite Pessoa M, Franco Costa Lima C, Farias Pimentel AC, Godeiro Costa JC, Bezerra Holanda JL. Multisystemic infarctions in COVID-19: focus on the spleen. Eur J Case Rep Intern Med. 2020;7(7):001747.

67 de Barry O, Mekki A, Diffre C, Seror M, El Hajjam M, Carlier RY. Arterial and venous abdominal thrombosis in a 79-year-old woman with COVID-19 pneumonia. Radiol Case Rep. 2020;15(7):1054-7.

68 La Mura V, Artoni A, Martinelli I, Rossio R, Gualtierotti R, Ghigliazza G, et al. Acute portal vein thrombosis in SARS-CoV-2 infection: a case report. Am J Gastroenterol. 2020; 115(7):1140-2.

69 Jafari SH, Naseri R, Khalili N, Haseli S, Bahmani M. Portal vein thrombosis associated with COVID-19: points to consider. BJR Case Rep. 2020;6(3):20200089.

70 Mohammadi S, Abouzaripour M, Hesam Shariati N, Hesam Shariati MB. Ovarian vein thrombosis after coronavirus disease (COVID-19) infection in a pregnant woman: case report. J Thromb Thrombolysis. 2020;50(3): 604-7. 
71 Giacomelli E, Dorigo W, Fargion A, Calugi G, Cianchi G, Pratesi C. Acute thrombosis of an aortic prosthetic graft in a patient with severe COVID-19-related pneumonia. Ann Vasc Surg. 2020;66:8-10.

72 Dhakal P, Khadka S, Clowes JA, Chakinala RC. Aortitis in COVID-19. IDCases. 2021;24: e01063.

73 Anand ER, Major C, Pickering O, Nelson M. Acute pancreatitis in a COVID-19 patient. $\mathrm{Br}$ J Surg. 2020;107(7):e182.

74 Brikman S, Denysova V, Menzal H, Dori G. Acute pancreatitis in a 61-year-old man with COVID-19. CMAJ. 2020;192(30):E858-9.

75 Liu F, Long X, Zhang B, Zhang W, Chen X, Zhang Z. ACE2 expression in pancreas may cause pancreatic damage after SARS-CoV-2 infection. Clin Gastroenterol Hepatol. 2020; 18(9):2128-30.e2.

76 Aloysius MM, Thatti A, Gupta A, Sharma N, Bansal P, Goyal H. COVID-19 presenting as acute pancreatitis. Pancreatology. 2020;20(5): 1026-7.

77 Pinte L, Baicus C. Pancreatic involvement in SARS-CoV-2: case report and living review. J Gastrointestin Liver Dis. 2020;29(2):275-6.

78 Hadi A, Werge M, Kristiansen KT, Pedersen UG, Karstensen JG, Novovic S, et al. Coronavirus disease-19 (COVID-19) associated with severe acute pancreatitis: case report on three family members. Pancreatology. 2020;20(4): 665-7.

79 Schreckenbach T, Fritsch N, Lahrsow M. SARS-CoV-2 pandemic: a complicated case of appendicitis. Dtsch Arztebl Int. 2020 May 15;117(20):364

80 Kumaran NK, Karmakar BK, Taylor OM. Coronavirus disease-19 (COVID-19) associated with acute umberzing pancreatitis (ANP). BMJ Case Rep. 2020;13(9):e237903.

81 Kataria S, Sharif A, Ur Rehman A, Ahmed Z, Hanan A. COVID-19 induced acute pancreatitis: a case report and literature review. $\mathrm{Cu}$ reus. 2020 Jul 13;12(7):e9169.

82 Ghosh A, Gupta V, Misra A. COVID19 induced acute pancreatitis and pancreatic necrosis in a patient with type 2 diabetes. Diabetes Metab Syndr. 2020;14(6):2097-8.

83 Purayil N, Sirajudeen J, VA N, Mathew J. COVID-19 presenting as acute abdominal pain: a case report. Cureus. 2020 Aug;12(8):e9659.

84 Shiralkar K, Chinapuvvula N, Ocazionez D. Cross-sectional abdominal imaging findings in patients with COVID-19. Cureus. 2020 Aug 3;12(8):e9538.

85 Cheung S, Delgado Fuentes A, Fetterman AD. Recurrent acute pancreatitis in a patient with COVID-19 infection. Am J Case Rep. 2020; 21:e927076

86 AlHarmi RAR, Fateel T, Sayed Adnan J, AlAwadhi K. Acute pancreatitis in a patient with COVID-19. BMJ Case Rep. 2021;14(2): e239656.

87 Sandhu H, Mallik D, Lokavarapu M, Huda F, Basu S. Acute recurrent pancreatitis and COVID-19 infection: a case report with literature review. Cureus. 2021 Feb 22;13(2):e13490.

88 Alves AM, Yvamoto EY, Marzinotto MAN, Teixeira ACS, Carrilho FJ. SARS-CoV-2 leading to acute pancreatitis: an unusual presentation. Braz J Infect Dis. 2020;24(6):561-4.
89 Schepis T, Larghi A, Papa A, Miele L, Panzuto F, De Biase L, et al. SARS-CoV2 RNA detection in a pancreatic pseudocyst sample. Pancreatology. 2020;20(5):1011-2.

90 Hassani AH, Beheshti A, Almasi F, Ketabi Moghaddam P, Azizi M, Shahrokh S. Unusual gastrointestinal manifestations of COVID-19: two case reports. Gastroenterol Hepatol Bed Bench. 2020;13(4):410-4.

91 Kumar R, Guruparan T, Siddiqi S, Sheth R, Jacyna M, Naghibi M, et al. A case of adrenal infarction in a patient with COVID 19 infection. BJR Case Rep. 2020;6(3):20200075.

92 Frankel M, Feldman I, Levine M, Frank Y, Bogot NR, Benjaminov O, et al. Bilateral adrenal hemorrhage in coronavirus disease 2019 patient: a case report. J Clin Endocrinol Metab. 2020;105(12):3745-9.

93 Peleg Y, Kudose S, D’Agati V, Siddall E, Ahmad S, Kisselev S, et al. Acute kidney injury due to collapsing glomerulopathy following COVID-19 infection. Kidney Int Rep. 2020; 5(6):940-5.

94 La Marca A, Busani S, Donno V, Guaraldi G, Ligabue G, Girardis M. Testicular pain as an unusual presentation of COVID-19: a brief review of SARS-CoV-2 and the testis. Reprod Biomed Online. 2020;41(5):903-6.

95 Bruni A, Garofalo E, Zuccalà V, Currò G, Torti C, Navarra G, et al. Histopathological findings in a COVID-19 patient affected by ischemic gangrenous cholecystitis. World J Emerg Surg. 2020;15(1):43.

96 Balaphas A, Gkoufa K, Meyer J, Peloso A, Bornand A, McKee TA, et al. COVID-19 can mimic acute cholecystitis and is associated with the presence of viral RNA in the gallbladder wall. J Hepatol. 2020;73(6): 1566-8.

97 Mattone E, Sofia M, Schembari E, Palumbo V, Bonaccorso R, Randazzo V, et al. Acute acalculous cholecystitis on a COVID-19 patient: a case report. Ann Med Surg. 2020;58: $73-5$.

98 Suwanwongse K, Shabarek N. Pseudo-appendicitis in an adolescent with COVID-19 Cureus. 2020 Jul;12(7):e9394.

99 Meireles PA, Bessa F, Gaspar P, Parreira I, Silva VD, Mota C, et al. Acalculous acute pancreatitis in a COVID-19 patient. Eur J Case Rep Intern Med. 2020;7(6):001710.

100 Guotao L, Xingpeng Z, Zhihui D, Huirui W. SARS-CoV-2 infection presenting with hematochezia. Med Mal Infect. 2020;50(3): 293-6.

101 Walpole SC, McHugh R, Samuel J, Schmid ML. COVID-19 presenting as severe, persistent abdominal pain and causing late respiratory compromise in a 33-year-old man. BMJ Case Rep. 2020;13(6):e236030.

102 Aiello P, Johnson S, Ramos Mercado A, Hussein S. Pneumatosis intestinalis in a patient with COVID-19. BMJ Case Rep. 2020; 13(9):e237564.

103 Wong K, Kim D, Khanijo S, Melamud A, Zaidi G. Pneumatosis intestinalis in COVID-19 case series. Cureus. 2020 Oct 16; 12(10):e10991.

104 Lakshmanan S, Toubia N. Pneumatosis intestinalis in COVID-19. Clin Gastroenterol Hepatol. 2020 May 30. Epub ahead of print.
105 Pérez Naranjo P, Moya Sánchez E, Férnandez Navarro L. Pneumatosis intestinalis as an incidental finding in a patient with $\mathrm{CO}$ VID-19 infection. Rev Esp Enferm Dig. 2021 Feb 26.

106 Horvat N, Pinto PVA, Araujo-Filho JAB, Santos JMMM, Dias AB, Miranda JA, et al. Abdominal gastrointestinal imaging findings on computed tomography in patients with COVID-19 and correlation with clinical outcomes. Eur J Radiol Open. 2021;8: 100326 .

107 Sahn B, Eze O, Edelman M, Chougar C Thomas R, Schleien C, et al. Features of intestinal disease associated with COVID-related multisystem inflammatory syndrome in children. J Pediatr Gastroenterol Nutr. 2021 Mar 1;72(3):384-7.

108 Miller J, Cantor A, Zachariah P, Ahn D, Martinez M, Margolis K. Gastrointestinal symptoms as a major presentation component of a novel multisystem inflammatory syndrome in children that is related to coronavirus disease 2019: a single center experience of 44 cases. Gastroenterology. 2020; 159(4):1571-4.e2.

109 Blumfield E, Levin TL, Kurian J, Lee EY, Liszewski MC. Imaging findings in multisystem inflammatory syndrome in children (MIS-C) associated with coronavirus disease (COVID-19). AJR Am J Roentgenol. 2021;216(2):507-17.

110 Tullie L, Ford K, Bisharat M, Watson T, Thakkar H, Mullassery D, et al. Gastrointestinal features in children with COVID-19: an observation of varied presentation in eight children. Lancet Child Adolesc Health. 2020;4(7):e19-20.

111 Cabrero-Hernández M, García-Salido A, Leoz-Gordillo I, Alonso-Cadenas J, GochiValdovinos A, González Brabin A, et al. Severe SARS-CoV-2 infection in children with suspected acute abdomen: a case series from a tertiary hospital in Spain. Pediatric Infectious Disease Journal. 2020;39(8):e195e198.

112 Riphagen S, Gomez X, Gonzalez-Martinez C, Wilkinson N, Theocharis P. Hyperinflammatory shock in children during COVID-19 pandemic.Lancet.2020;395(10237): 1607-8.

113 Rohani P, Karimi A, Tabatabaie SR, Khalili M, Sayyari A. Protein losing enteropathy and pneumatosis intestinalis in a child with COVID 19 infection. J Pediatr Surg Case Rep. 2021;64:101667.

114 Makrinioti H, MacDonald A, Lu X, Wallace $\mathrm{S}$, Jobson $\mathrm{M}$, Zhang $\mathrm{F}$, et al. Intussusception in 2 children with severe acute respiratory syndrome coronavirus-2 infection. J Pediatric Infect Dis Soc. 2020;9(4):504-6.

115 Athamnah MN, Masade S, Hamdallah H, Banikhaled N, Shatnawi W, Elmughrabi M, et al. COVID-19 presenting as intussusception in infants: a case report with literature review. J Pediatr Surg Case Rep. 2021;66: 101779.

116 Martínez-Castaño I, Calabuig-Barbero E, Gonzálvez-Piñera J, López-Ayala JM. COVID-19 infection is a diagnostic challenge in infants with ileocecal intussusception. Pediatr Emerg Care. 2020;36(6):e368. 
117 Moazzam Z, Salim A, Ashraf A, Jehan F, Arshad $M$. Intussusception in an infant as a manifestation of COVID-19. J Pediatr Surg Case Rep. 2020;59:101533.

118 Rajalakshmi L, Satish S, Nandhini G, Ezhilarasi S. Unusual presentation of COVID-19 as intussusception. Indian J Pract Pediatr. 2020;22:236.

119 Bazuaye-Ekwuyasi EA, Camacho AC, Saenz Rios F, Torck A, Choi WJ, Aigbivbalu EE, et al. Intussusception in a child with COVID-19 in the USA. Emerg Radiol. 2020; 27(6):761-4.

120 Harwood R, Partridge R, Minford J, Almond S. Paediatric abdominal pain in the time of COVID-19: a new diagnostic dilemma. J Surg Case Rep. 2020;2020(9):rjaa337.

121 Samies NL, Yarbrough A, Boppana S. Pancreatitis in pediatric patients with $\mathrm{COV}$ -
ID-19. J Pediatric Infect Dis Soc. 2020;10(1): 57-9.

122 Gagliardi L, Bertacca C, Centenari C, Merusi I, Parolo E, Ragazzo V, et al. Orchiepididymitis in a boy with COVID-19. Pediatr Infect Dis J. 2020;39(8):e200-2.

123 Mehl SC, Whitlock RS, Marcano DC, Rialon KL, Arrington AS, Naik-Mathuria B. Necrotizing enterocolitis-like pneumatosis intestinalis in an infant with COVID-19. Pediatr Infect Dis J. 2020;40(2):e85-6.

124 Li G, He X, Zhang L, Ran Q, Wang J, Xiong A, et al. Assessing ACE2 expression patterns in lung tissues in the pathogenesis of COVID-19. J Autoimmun. 2020;112:102463.

125 Parasa S, Desai M, Thoguluva Chandrasekar V, Patel HK, Kennedy KF, Roesch T, et al. Prevalence of gastrointestinal symptoms and fecal viral shedding in patients with coronavirus disease 2019: a systematic review and meta-analysis. JAMA Netw Open. 2020;3(6):e2011335

126 Van Wissen M, Keller TT, Van Gorp EC, Gerdes VE, Meijers JC, Van Doornum GJ, et al. Acute respiratory tract infection leads to procoagulant changes in human subjects. J Thromb Haemost. 2011;9(7):1432-4.

127 Tan CW, Low JGH, Wong WH, Chua YY, Goh SL, Ng HJ. Critically ill COVID-19 infected patients exhibit increased clot waveform analysis parameters consistent with hypercoagulability. Am J Hematol. 2020; 95(7):E156.

128 El Moheb M, Naar L, Christensen MA, Kapoen C, Maurer LR, Farhat M, et al. Gastrointestinal complications in critically ill patients with and without COVID-19. JAMA. 2020;324(18): 1899 . 